and by a deterioration in functionality and mental status. However, clinical form of $\mathrm{SpA}$, disease duration and structural damage in spine do not explain this decrease of QoL.

References:

[1] Machado P, Landewé R, Braun J, Hermann KG, Baraliakos X, Baker D, et al: A stratified model for health outcomes in ankylosing spondylitis. Ann Rheum Dis 2011;70:1758-64.

[2] Fernández-Carbadillo C, Navarro-Compán V, Castillo-Gallego C, CastroVillegas MC, Collantes-Estévez E, de Miguel E. Disease activity is the major determinant of quality of life and physical function in patients with early axial Spondyloarthritis: Results from the ESPERANZA Cohort. Arthritis Care Res (Hoboken) 2016 Apr 25.1.

Disclosure of Interest: None declared

DOI: 10.1136/annrheumdis-2017-eular.2071

\section{FRI0435 COMPARISON BETWEEN CENTRAL AND LOCAL ASSESSMENT OF RADIOGRAPHIC SACROILIITIS IN PATIENTS WITH RECENTLY DIAGNOSED AXIAL SPONDYLOARTHRITIS IN PROOF STUDY}

D. Poddubnyy ${ }^{1}$, R.D. Inman ${ }^{2}$, J. Sieper ${ }^{1}$, H. Haibel ${ }^{1}$, M. Hojnik ${ }^{3} \cdot{ }^{1}$ Charité Universitätsmedizin Berlin, Berlin, Germany; ${ }^{2}$ Toronto Western Hospital, Toronto, Canada; ${ }^{3}$ AbbVie, Ljubljana, Slovenia

Background: High inter-reader variability of radiographic sacroiliitis assessment has been reported in a number of previous studies, suggesting its low reliability for the diagnosing and classification of axial spondyloarthritis (axSpA).

Objectives: To compare the results of local versus central scoring of radiographic sacroiliitis in a large multinational cohort of patients (pts) with recently diagnosed axSpA.

Methods: PROOF is a prospective observational study evaluating clinical and radiographic outcomes in axSpA pts in rheumatology clinical practice in 29 countries. Pts with axSpA fulfilling ASAS classification criteria were eligible if diagnosed $\leq 1$ year prior to study enrolment. Radiographs of sacroiliac joints (SIJ) collected at baseline were graded according to the modified New York (mNY) criteria ( $0-4$ for each SIJ). Pts with sacroiliitis of grade $\geq 2$ bilaterally or grade $\geq 3$ unilaterally were classified as ankylosing spondylitis (AS); otherwise pts were classified as non-radiographic axSpA (nr-axSpA). All available radiographs were assessed first by a local reader (LR) and then by a central reader (CR1), who was blinded to the results of the LR. In the case of a disagreement in the classification (AS or nr-axSpA), the radiograph was evaluated by the 2 nd central reader (CR2), who was blinded to the previous assessments and the final classification was made based on the decision of 2 out of 3 readers.

Results: Of the 2126 pts enrolled in PROOF, 1583 were included in this analysis based on evaluable radiographs of the SIJ. Based on the LR judgment, 987 pts were classified as AS and 596 as nr-axSpA, while 1158 were classified as AS and 425 as nr-axSpA according to CR1. Following CR1 assessment, 1146 (72.4\%) pts retained their LR classification, while 437 (27.6\%) pts were classified differently. Of the 437 pts with discrepant classification assessed by CR2, 175 $(40 \%)$ retained their initial LR classification and $265(60 \%)$ were re-classified. The agreement between the CR1 and CR2 (kappa=0.24 [95\% Cl: 0.17-0.32]) was lower than between LR and CR1 (kappa=0.38 [95\% Cl: 0.33-0.42]). Finally, 1039

Figure. Final Classification of Patients with axSpA in Relation to Their Initial Local Classification in the PROOF Study Based on the Assessment of the Radiographic Changes in the Sacroiliac Joints.

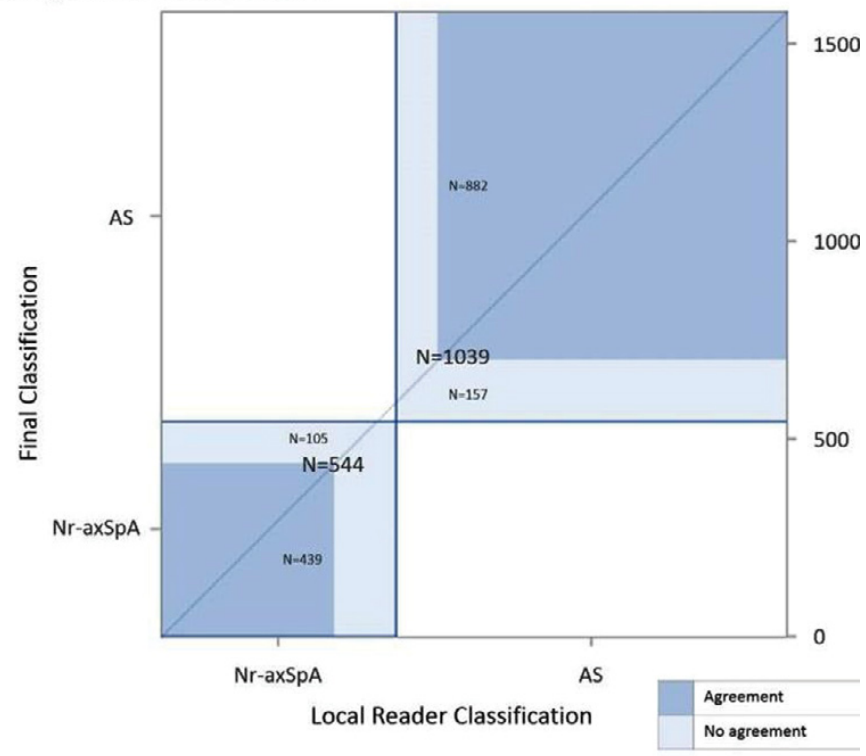

$A S=$ ankylosing spondylitis; $n r-a x S p A=$ non-radiographic axial spondyloarthritis pts were classified as AS and 544 as axSpA; 1321 (83.5\%) pts retained their initial classification and $262(16.5 \%)$ were re-classified (157 from nr-axSpA to $\mathrm{AS}$ and 105 from AS to nr-axSpA). There was a substantial agreement between local and final central classification (kappa $=0.64$ [95\% $\mathrm{Cl}: 0.60-0.68]$, Figure). Importantly, pts initially classified by a LR as nr-axSpA (157/596, 26.3\%) had significantly higher odds (odds ratio=3.0 $(95 \% \mathrm{Cl}: 2.3-3.9)$ of being re-classified compared with pts classified as AS (105/987, 10.6\%).

Conclusions: In the PROOF study, the agreement between local and central classification of pts with axSpA (nr-axSpA vs AS) based on the grading of SIJ radiographs by $\mathrm{mNY}$ criteria was reasonably good. Pts locally classified as $n r-a x S p A$ were three times more likely to be re-classified compared with AS pts, which may be related to difficulty in the assessment of less advanced structural changes.

Acknowledgements: AbbVie funded the PROOF study, contributed to its design and participated in data collection, analysis and interpretation of the data, and in writing, review, and approval of the publication. Medical writing support was provided by Deepa Venkitaramani, PhD, of AbbVie.

Disclosure of Interest: D. Poddubnyy Grant/research support from: AbbVie, Janssen, MSD, Novartis, Pfizer, Consultant for: AbbVie, BMS, Boehringer, MSD, Novartis, Pfizer, and UCB, Speakers bureau: AbbVie, BMS, Janssen, MSD, Novartis, Pfizer, Roche, and UCB, R. Inman Grant/research support from: AbbVie, Amgen, and Janssen, Consultant for: AbbVie, Amgen, Janssen, Lilly, Novartis, and Pfizer, J. Sieper Grant/research support from: AbbVie, Merck, and Pfizer, Consultant for: AbbVie, Janssen, Lilly, Merck, Novartis, Pfizer, and UCB, Speakers bureau: AbbVie, Janssen, Merck, Novartis, Pfizer, Roche, and UCB, H. Haibel Consultant for: Boehringer, MSD, and Novartis, Speakers bureau: AbbVie, MSD, and Pfizer., M. Hojnik Shareholder of: AbbVie, Employee of: AbbVie DOI: 10.1136/annrheumdis-2017-eular.1578

\section{FRI0436 CHRONIC PAIN IN PATIENTS WITH ESTABLISHED AXIAL SPONDYLOARTHRITIS AND ASSESSMENT OF PAIN SENSITIVITY BY COMPUTERIZED PNEUMATIC CUFF PRESSURE ALGOMETRY: RESULTS FROM THE SPARTAKUS COHORT}

E. Mogard ${ }^{1}$, T. Olofsson ${ }^{1}$, A. Bremander ${ }^{2}$, S. Bergman ${ }^{3}$, L.-E. Kristensen ${ }^{4}$ J. Kvistgaard Olsen ${ }^{4}$, J.K. Wallman ${ }^{1}$, E. Lindqvist ${ }^{1} .{ }^{1} / \mathrm{KVL}$, Department of Rheumatology, Lund University, Lund; ${ }^{2}$ School of Business, Engineering and Science, Halmstad University, Halmstad; ${ }^{3}$ Primary health care unit, Department of Public Health and Community Medicine, Institute of Medicine, Sahlgrenska Academy, University of Gothenburg, Gothenburg, Sweden; ${ }^{4}$ The Parker Institute, Department of Rheumatology, Copenhagen University Hospital Fredriksberg and Bispebjerg, Copenhagen, Denmark

Background: Pain is a common symptom in all arthritides, and remains a problem also with better treatment options. In axial spondyloarthritis (ax-SpA), data on chronic pain remain scarce.

Objectives: To study pain distribution, duration and intensity in ax-SpA, and relate this to disease status and measurement of pressure pain sensitivity.

Methods: Consecutive patients $(n=115)$ with clinical ax-SpA diagnoses (ankylosing spondylitis (AS) or undifferentiated axial spondyloarthritis (USpA)) were examined and answered pain questionnaires. Patients were categorised as having no chronic pain (NCP), chronic regional pain (CRP) or chronic widespread pain (CWP). Pressure pain sensitivity was assessed by computerized pneumatic cuff pressure algometry (CPA) on the dominant lower leg, and pain threshold, pain tolerance and temporal summation (assessed by the temporal summation index, TSI) were recorded. Differences in disease status and pressure pain sensitivity between patients with CWP versus NCP were assessed (Chi-square or MannWhitney U-test). Pressure pain sensitivity was also compared between patients with/without unacceptable pain levels (VAS pain $>40$ versus $\leq 40$; Mann-Whitney U-test).

Results: Fifty percent of patients reported CWP, irrespective of clinical diagnosis (AS 47\%, USpA 53\%), and more women than men reported CWP (59\% versus $37 \%, p<0.001)$. Only $18 \%$ of all patients reported NCP. Overall, higher disease

\begin{tabular}{lccccc}
\hline Mean (SD) unless indicated & $\begin{array}{c}\text { All } \\
\text { cases } \\
\mathrm{n}=115\end{array}$ & $\begin{array}{c}\text { Non } \\
\text { chronic } \\
\text { pain (NCP) } \\
\mathrm{n}=20\end{array}$ & $\begin{array}{c}\text { Chronic } \\
\text { regional } \\
\text { pain (CRP) } \\
\mathrm{n}=38\end{array}$ & $\begin{array}{c}\text { Chronic } \\
\text { widespread } \\
\text { pain (CWP) } \\
\mathrm{n}=57\end{array}$ & $\begin{array}{c}\text { NCP vs CWP } \\
\text { p value }\end{array}$ \\
\hline Female sex, $\mathrm{n}(\%)$ & $66(57)$ & $6(30)$ & $21(55)$ & $39(68)$ & 0.004 \\
Age, years, years & $53(13)$ & $52(16)$ & $49(13)$ & $55(12)$ & 0.384 \\
Disease duration, years & $25(14)$ & $24(14)$ & $22(13)$ & $29(14)$ & 0.148 \\
HLA-B27 positive, yes (\%) & $83(74)$ & $14(78)$ & $30(79)$ & $39(68)$ & 0.560 \\
AS/USpA (ICD-10) $\mathrm{n}$ & $60 / 55$ & $13 / 7$ & $19 / 19$ & $28 / 29$ & 0.299 \\
VAS pain, 0-100 & $37(27)$ & $15(18)$ & $32(26)$ & $49(24)$ & $<0.001$ \\
VAS global & $38(26)$ & $19(22)$ & $32(26)$ & $48(22)$ & $<0.001$ \\
VAS fatigue & $40(28)$ & $23(23)$ & $33(28)$ & $51(26)$ & $<0.001$ \\
BASDAl & $3.5(2.3)$ & $1.6(1.6)$ & $3.0(2.0)$ & $4.9(2.1)$ & $<0.001$ \\
BASFI & $2.5(2.4)$ & $1.1(1.4)$ & $1.8(2.3)$ & $3.7(2.4)$ & $<0.001$ \\
BASMI & $3.1(1.6)$ & $2.9(1.6)$ & $2.9(1.9)$ & $3.3(1.4)$ & 0.255 \\
ASDAS-CRP & $2.1(1.0)$ & $1.2(0.7)$ & $1.8(0.9)$ & $2.7(0.8)$ & $<0.001$ \\
Pain threshold ,kPa & $30.1(14.4)$ & $33.7(18.1)$ & $30.7(11.5)$ & $27.8(14.8)$ & 0.216 \\
Pain tolerance, kPa & $62.1(26.5)$ & $71.6(29.5)$ & $63.0(25.0)$ & $56.8(25.6)$ & 0.069 \\
TSI & $0.60(0.59)$ & $0.53(0.46)$ & $0.60(0.57)$ & $0.63(0.66)$ & 0.189 \\
\hline
\end{tabular}

